\title{
openheart Effects of intravenous caffeine on fractional flow reserve measurements in coronary artery disease
}

\author{
Vivek Mutha, ${ }^{1}$ Muhammad Asrar ul Haq, ${ }^{1,2}$ William J Van Gaal ${ }^{1}$
}

To cite: Mutha V, Asrar ul Haq M, Van Gaal WJ. Effects of intravenous caffeine on fractional flow reserve measurements in coronary artery disease. Open Heart 2014:1:e00060.

doi:10.1136/openhrt-2014000060

Received 17 February 2014 Revised 17 June 2014 Accepted 15 July 2014
CrossMark

\footnotetext{
${ }^{1}$ Department of Cardiology, The Northern Hospital, Melbourne, Victoria, Australia ${ }^{2}$ Department of Medicine, University of Melbourne, Melbourne, Victoria, Australia

Correspondence to Dr Muhammad Asrar ul Haq; muhammad.asrar@unimelb. edu.au
}

\section{ABSTRACT \\ Background: Intravenous adenosine is used to minimise the coronary micro-resistance to achieve maximal hyperaemia along with nitrates for optimal fractional flow reserve (FFR) measurements. We hypothesise that caffeine, being a competitive inhibitor of adenosine, would influence adenosine-mediated FFR readings.}

Methods: Consecutive patients undergoing angiogram and FFR measurements were enrolled after abstaining from caffeine for $24 \mathrm{~h}$. Patients with any contraindications to intravenous adenosine or caffeine were excluded. FFR measurements were taken using nitrates and adenosine pre and post $4 \mathrm{mg} / \mathrm{kg}$ intravenous caffeine administration and results were compared.

Results: 10 patients were analysed (80\% men, age 59.9 \pm 9.4 , weight $87.5 \pm 15.6$ ). Baseline caffeine levels were undetectable in all patients and increased significantly postintravenous caffeine administration $(16.4 \pm 5.5 \mu \mathrm{g} /$ $\mathrm{mL})$. Baseline preadenosine FFR values were similar before and after caffeine administration $(0.91 \pm 0.06$ vs $0.91 \pm 0.07 ; p=0.41)$. Postadenosine FFR readings were $0.79 \pm 0.07$, which increased non-significantly to 0.82 \pm 0.11 postcaffeine $(p=0.15)$. Two significant FFR readings $(\leq 0.8)$ changed to non-significant after caffeine administration (0.77-0.93 and 0.8-0.91).

Conclusions: Caffeine may affect FFR results in some patients. Larger studies are warranted to clarify the extent and magnitude of caffeine/adenosine interaction particularly due to ubiquitous nature of caffeine and increasing importance of FFR in clinical practice.

\section{INTRODUCTION}

Fractional flow reserve (FFR)-guided percutaneous intervention (PCI) improves outcomes in patients with stable and unstable angina. ${ }^{12}$ Maximal hyperaemia is paramount for optimal FFR measurements. Intravenous adenosine is the most widely used agent to minimise the coronary micro-resistance and thus induce maximal hyperaemia along with intracoronary nitroglycerine. ${ }^{3}$

Caffeine is a methylxanthine commonly found in tea, coffee and chocolate. Caffeine is a competitive inhibitor of adenosine A2a receptor at the cellular level. ${ }^{4}$ Patients

\section{KEY MESSAGES}

What is already known about this subject?

- Caffeine is a competitive inhibitor of adenosine and can potentially impact on the fractional flow reserve (FFR) results. Patients undergoing adenosine perfusion scintigraphy studies are required to abstain from caffeine for at least 12 hours prior to the test. However, no such guidelines exist for FFR measurements.

What does this study add?

- Based on our findings it may be hypothesized that sensitivity of caffeine and its inhibitory effect on adenosine can vary between the individuals and has potential to alter the FFR results. Further trials are required to confirm these findings.

How might this impact on clinical practice?

- A caffeine history may be considered in people undergoing FFR measurements, particularly in context of an unexpected FFR result.

undergoing adenosine perfusion scintigraphy studies are required to abstain from caffeine for at least $12 \mathrm{~h}$ prior to the test. ${ }^{5}$ However, no such guidelines exist for FFR measurements. We hypothesise that caffeine, being a competitive inhibitor of adenosine, would influence adenosine-mediated FFR readings.

\section{METHODS}

\section{Study population}

Consecutive patients undergoing standard of care angiogram and FFR measurements to investigate intermediate coronary artery lesion were recruited to participate. Patients with any contraindications to intravenous adenosine or caffeine were excluded, as well as patients with normal or near normal FFR $(>0.9$; figure 1$)$. Participants were required to abstain from caffeine (tea, coffee and chocolate) for $24 \mathrm{~h}$ prior to FFR measurements.

\section{Angiography and baseline FFR}

Angiography was performed via right radial or right femoral approach. After guide 
catheter placement, intracoronary nitroglycerine $(200 \mu \mathrm{g})$ was administered and repeat angiographic images were obtained to confirm lesion severity. FFR was measured using a 0.014-inch pressure guidewire (St Jude Medical, Minneapolis, Minnesota, USA) after a $3 \mathrm{~min}$ peripheral intravenous infusion of adenosine $(140 \mu \mathrm{g} /$ $\mathrm{kg} / \mathrm{min}$ ). The lowest FFR reading over $3 \mathrm{~min}$ of adenosine infusion was recorded. All FFR tracings were analysed to ensure absence of artefacts.

\section{Intravenous caffeine and repeat FFR measurements}

A period of $3 \mathrm{~min}$ was prescribed to allow postadenosine FFR to return to baseline levels. Intravenous caffeine, roughly equivalent of 3-4 cups of average coffee ( $4 \mathrm{mg}$ / $\mathrm{kg}){ }^{6}$, was injected over $1 \mathrm{~min}$ after obtaining blood samples for baseline caffeine level. Peak caffeine level blood samples were collected after $5 \mathrm{~min}$. A repeat FFR measurement was then performed utilising the same protocol within 12-15 min of initial FFR measurement (figure 1).

\section{Statistical analysis}

All data were analysed using SPSS Statistics Software (IBM, Windows, V.19). Data are presented as values and percentages or mean value \pm SD. Paired $t$ test was used to compare continuous data. A two-tailed $\mathrm{p}$ value of $<0.05$ was considered statistically significant.

\section{Ethical consideration}

Therapeutic Goods Administration (TGA, Australia) exemption was sought and obtained to use intravenous caffeine for non-approved trial indication. Informed written consent was obtained from all patients.

\section{RESULTS}

Two patients were excluded as their baseline adenosine FFR was $>0.9$. A total of 10 patients were enrolled. Baseline characteristics of these patients are described in table 1 . Mean coffee consumption was $2.85 \pm 1.02$ cups a day. Individual FFR results are summarised in the table 2. Baseline caffeine levels were undetectable $(<5 \mu \mathrm{g} / \mathrm{mL})$ in

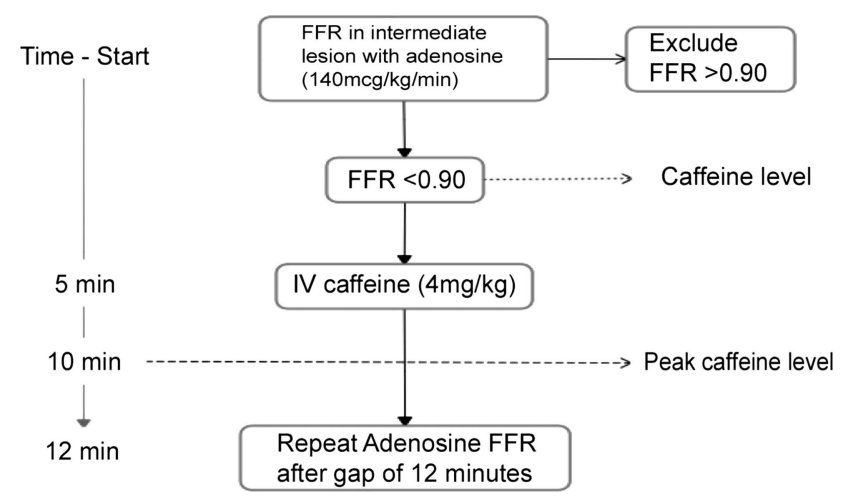

Figure 1 Protocol (IV, intravenous; FFR, fractional flow reserve).
Table 1 Baseline characteristics

\begin{tabular}{ll}
\hline Age & $59.9 \pm 9.4$ \\
Males & $80 \%$ \\
Weight & $87.5 \pm 15.6$ \\
Hypertension & $70 \%$ \\
Diabetes & $30 \%$ \\
Smoking & $60 \%$ \\
Average coffee consumption & $2.85 \pm 1.02$ \\
ACE inhibitors/angiotensin receptor & $60 \%$ \\
blocker therapy & \\
$\beta$-blocker therapy & $40 \%$ \\
Aspirin therapy & $100 \%$ \\
Clopidogrel & $60 \%$ \\
Ticagrelor & $40 \%$ \\
Nitrates & $20 \%$ \\
Values expressed as mean \pm SD or percentage $(\%)$.
\end{tabular}

all patients and increased significantly postintravenous caffeine administration $(16.4 \pm 5.5 \mu \mathrm{g} / \mathrm{mL})$. Mean caffeine dosage administered was $348 \pm 41.3 \mathrm{mg}$. All patients reported flushing symptoms with initial adenosine infusion which were markedly less with repeat adenosine infusion postintravenous caffeine on subjective assessment.

Baseline preadenosine FFR values were similar before and after caffeine administration $(0.91 \pm 0.06$ vs 0.91 $\pm 0.07 ; \mathrm{p}=0.41$ ). Postadenosine FFR readings were 0.79 \pm 0.07 , which non-significantly increased to $0.82 \pm 0.11$ postcaffeine $(\mathrm{p}=0.15)$. Interestingly, significant FFR values $(\leq 0.8)^{2}$ for two patients changed to nonsignificant after caffeine administration $(0.77-0.93$ and 0.8-0.91; figure 2). Graphical representation of individual results before and after caffeine is shown in figure 3 . There was no relation noted between average baseline coffee consumption $(2.85 \pm 1.02$ cups $)$ and affect to intravenous caffeine on FFR.

\section{DISCUSSION}

Our study demonstrates higher average FFR readings after caffeine administration in $7(70 \%)$ patients using intravenous adenosine when compared with baseline readings. Although this difference did not reach statistical significance over all, it potentially can be clinically relevant in selected individuals, as two patients' results changed from positive ${ }^{2} \quad(\leq 0.8)$ to negative $(>0.8)$. Baseline (preadenosine) readings for both FFR measurements remained unchanged suggestive of caffeine being the causative factor for the change. FFR readings of two patients were decreased after caffeine, the reason of which is unclear. These two patients had significantly positive FFR readings at baseline, which despite the change remained positive after caffeine.

A previous study to elucidate the effect of caffeine on FFR did not show a difference using intracoronary adenosine as a hyperaemic agent. ${ }^{4}$ Although there have been a multitude of studies comparing intravenous and 


\begin{tabular}{|c|c|c|c|c|c|c|c|c|}
\hline $\mathbf{N}$ & Sex & Age & Vessel & $\begin{array}{l}\text { Peak caffeine } \\
\text { levels. }(\mu \mathrm{g} / \mathrm{mL})\end{array}$ & $\begin{array}{l}\text { Baseline FFR } \\
\text { (preadenosine) }\end{array}$ & $\begin{array}{l}\text { Repeat baseline } \\
\text { FFR (postcaffeine, } \\
\text { preadenosine) }\end{array}$ & $\begin{array}{l}\text { Baseline FFR } \\
\text { (postadenosine) }\end{array}$ & $\begin{array}{l}\text { Postcaffeine } \\
\text { FFR } \\
\text { (postadenosine) }\end{array}$ \\
\hline 1 & $M$ & 57 & Mid RCA & 26.4 & 0.92 & 0.92 & 0.80 & 0.91 \\
\hline 2 & $M$ & 73 & Mid LAD & 11.8 & 0.93 & 0.93 & 0.77 & 0.93 \\
\hline 3 & $M$ & 58 & Prox LAD & 15.5 & 0.95 & 0.95 & 0.85 & 0.87 \\
\hline 4 & $M$ & 60 & Mid RCA & 12.6 & 0.90 & 0.81 & 0.74 & 0.75 \\
\hline 5 & $M$ & 49 & Prox LAD & 18.2 & 0.80 & 0.81 & 0.69 & 0.61 \\
\hline 6 & $M$ & 58 & Distal RCA & 12.4 & 0.80 & 0.81 & 0.69 & 0.67 \\
\hline 7 & $M$ & 45 & Mid LAD & 15.3 & 0.93 & 0.92 & 0.86 & 0.87 \\
\hline 8 & $\mathrm{~F}$ & 76 & Mid RCA & 15.9 & 0.97 & 0.97 & 0.81 & 0.81 \\
\hline 9 & $\mathrm{~F}$ & 59 & Mid LAD & 10.5 & 0.97 & 0.97 & 0.87 & 0.95 \\
\hline 10 & $M$ & 64 & Prox RCA & 25.4 & 0.97 & 0.97 & 0.82 & 0.87 \\
\hline
\end{tabular}

FFR, fractional flow reserve.

Figure 2 Adenosine fractional flow reserve (FFR) tracings of a patient reading 0.77 before caffeine $(A)$ which changed to insignificant value of 0.93 after caffeine (B).

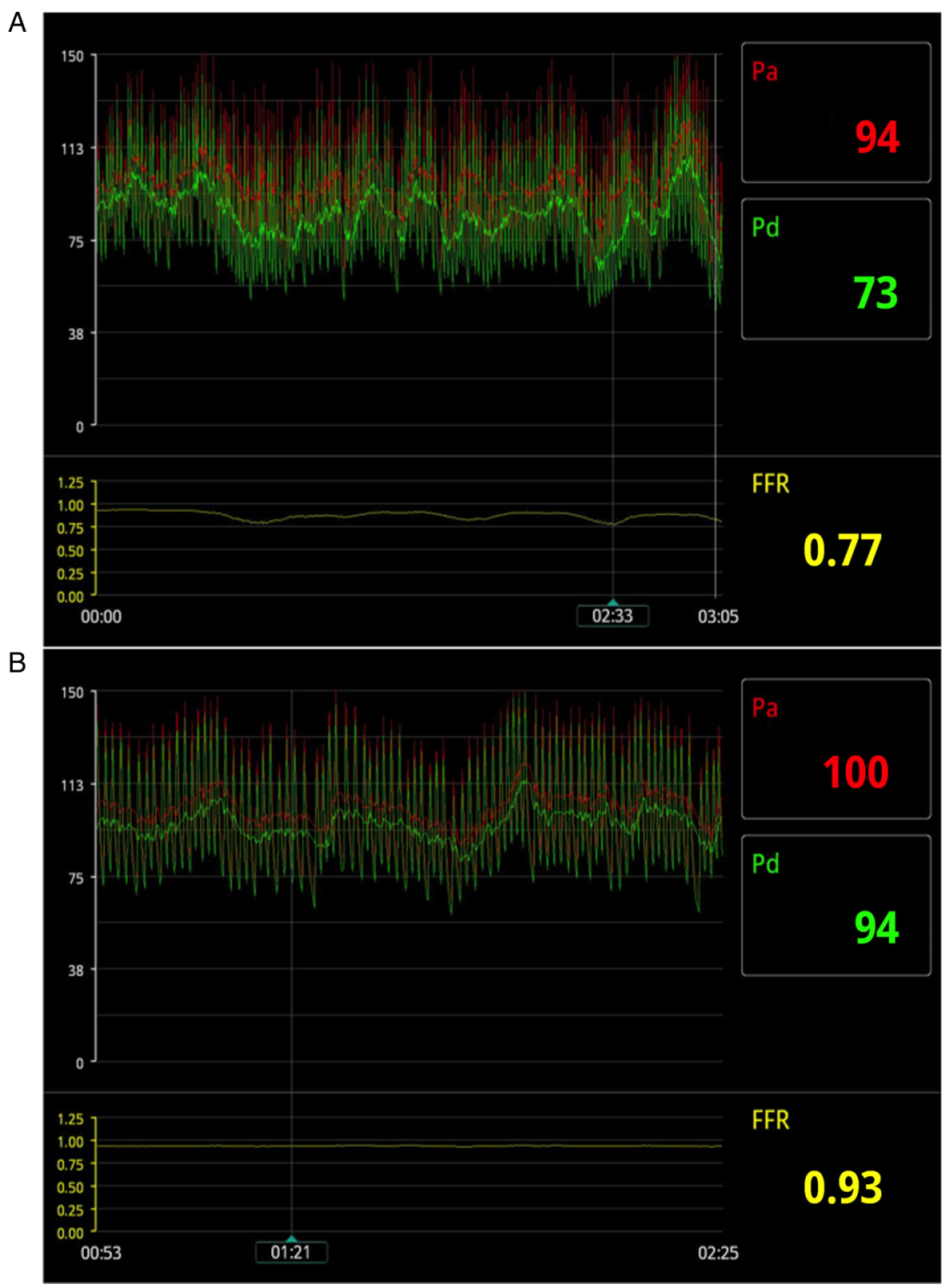


Figure 3 Graphical fractional flow reserve (FFR) results before and after caffeine. representation of individual

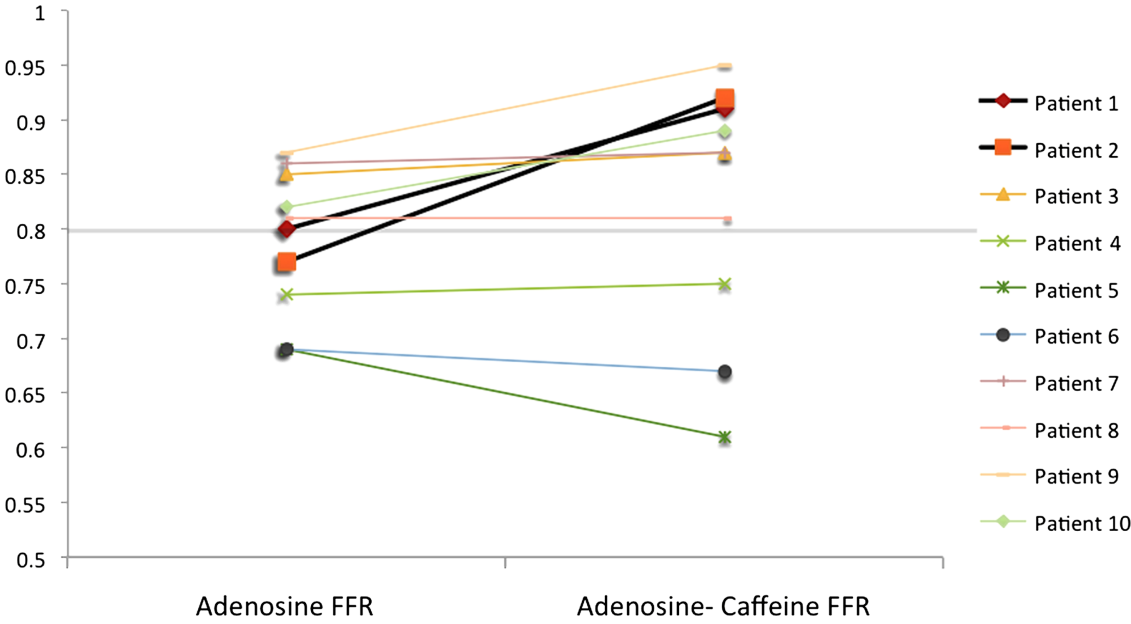

intracoronary adenosine, intravenous adenosine is the most widely used method for inducing maximal hyperaemia. ${ }^{3}$

The competitive inhibition of adenosine A2a receptors with caffeine has been studied in a number of adenosine nuclear perfusion studies with mixed outcomes. ${ }^{7} 8$ Higher doses of adenosine $(210 \mu \mathrm{g} / \mathrm{kg} / \mathrm{min})$ have been used by few to overcome the effect of caffeine on adenosine nuclear perfusion studies. ${ }^{8}$ Though our study did not include higher dose adenosine, it is plausible that similar effect may be seen in FFR readings. Further studies are needed to evaluate that.

Our study is limited by power to achieve any definitive conclusive results. Furthermore, orally consumed coffee or tea has other metabolites such as theophylline and theobromine that can have vasodilatory effects in addition to their adenosine inhibition similar to caffeine. Our study used intravenous caffeine administered over a short duration of time and may not have accounted for any additional effects of these metabolites on FFR. Another weakness of the study is that only 4 out of 10 patients had an FFR value $\leq 0.8$. It does however raise questions which require larger trials to clarify. The present practice across majority of cardiac catheterisation laboratories for elective FFR or PCI is though variable, mostly involves a fasting period of $>4 \mathrm{~h}$, and caffeine history is not routinely obtained. Based on our findings, it may be hypothesised that sensitivity of caffeine and its inhibitory effect on adenosine can vary between the individuals and has potential to alter the FFR results. A caffeine history may be considered particularly in context of an unexpected FFR result.

\section{CONCLUSION}

Caffeine may affect FFR results in some patients. A larger scale trial is needed to clarify the extent and magnitude of caffeine/adenosine interaction particularly due to ubiquitous nature of caffeine and increasing importance of FFR in clinical practice.
Funding This research received no specific grant from any funding agency in the public, commercial or not-for-profit sectors.

Competing interests None.

Ethics approval The study complied with the declaration of Helsinki and was approved by institutional ethics committee.

Provenance and peer review Not commissioned; externally peer reviewed.

Data sharing statement No additional data are available.

Open Access This is an Open Access article distributed in accordance with the Creative Commons Attribution Non Commercial (CC BY-NC 3.0) license, which permits others to distribute, remix, adapt, build upon this work noncommercially, and license their derivative works on different terms, provided the original work is properly cited and the use is non-commercial. See: http:// creativecommons.org/licenses/by-nc/3.0/

\section{REFERENCES}

1. Tonino PA, De Bruyne $\mathrm{B}, \mathrm{Pijls} \mathrm{NH}$, et al. Fractional flow reserve versus angiography for guiding percutaneous coronary intervention. N Engl J Med 2009;360:213-24.

2. De Bruyne B, Pijls NH, Kalesan B, et al. Fractional flow reserve-guided $\mathrm{PCl}$ versus medical therapy in stable coronary disease. N Engl J Med 2012;367:991-1001.

3. Jeremias A, Whitbourn RJ, Filardo SD, et al. Adequacy of intracoronary versus intravenous adenosine-induced maximal coronary hyperemia for fractional flow reserve measurements. Am Heart J 2000;140:651-7.

4. Aqel RA, Zoghbi GJ, Trimm JR, et al. Effect of caffeine administered intravenously on intracoronary-administered adenosine-induced coronary hemodynamics in patients with coronary artery disease. Am J Cardiol 2004:93:343-6.

5. Hendel RC, Berman DS, Di Carli MF, et al. ACCF/ASNC/ACR/AHA/ ASE/SCCT/SCMR/SNM 2009 appropriate use criteria for cardiac radionuclide imaging: a report of the American College of Cardiology Foundation Appropriate Use Criteria Task Force, the American Society of Nuclear Cardiology, the American College of Radiology, the American Heart Association, the American Society of Echocardiography, the Society of Cardiovascular Computed Tomography, the Society for Cardiovascular Magnetic Resonance, and the Society of Nuclear Medicine. Circulation 2009;119:e561-87.

6. Desbrow $B$, Hughes $R$, Leveritt $M$, et al. An examination of consumer exposure to caffeine from retail coffee outlets. Food Chem Toxicol 2007;45:1588-92.

7. Zoghbi GJ, Htay T, Aqel R, et al. Effect of caffeine on ischemia detection by adenosine single-photon emission computed 2006;47:2296-302.

8. Reyes $\mathrm{E}$, Loong $\mathrm{CY}$, Harbinson $\mathrm{M}$, et al. High-dose adenosine overcomes the attenuation of myocardial perfusion reserve caused by caffeine. J Am Coll Cardiol 2008;52:2008-16. tomography perfusion imaging. J Am Coll Cardiol 